\title{
GNAS Protein Variant
}

National Cancer Institute

\section{Source}

National Cancer Institute. GNAS Protein Variant. NCI Thesaurus. Code C146951.

A variation in the amino acid sequence for a protein encoded by the GNAS gene. 